\title{
LETTERS
}

\section{Strengthening tuberculosis surveillance in Canada}

March 24 was World Tuberculosis Day and Canada still has much to do to fulfil recent commitments ${ }^{1}$ to eliminate tuberculosis (TB), a disease that has long required collaboration and coherence to address effectively its multiple determinants. ${ }^{2,3}$ As suggested by Essue and colleagues in their CMAJ commentary, ${ }^{4}$ one way to do this is to work toward a consistent approach to surveillance to understand fully the portrait of tuberculosis (TB) in Canada, inform public health actions, and monitor the progress to reach pre-elimination of TB (defined by the World Health Organization [WHO] as less than 10 cases per million per year ${ }^{5}$ ). That approach should include aspiring to present and report disaggregated TB surveillance indicators routinely, including for latent TB infections. ${ }^{4}$

As the cases of multidrug-resistant TB increase, nation states and the WHO have reinforced their emphasis on reducing and eliminating TB. The WHO Framework Toward Tuberculosis Elimination in LowIncidence Countries includes specific recommendations for surveillance and monitoring, especially for men and women with latent TB infections, stating that "due consideration should be given to extending the range of variables beyond those usually collected in TB surveillance," including demographic, clinical, geopositioning, vital statistics and socioeconomic data. ${ }^{5}$ Some countries and regions have incorporated this approach in their most recent TB reports (e.g., Australia and England). ${ }^{6,7}$

Health system and related indicators for diagnosis, treatment and outcomes should be presented by sex, age, province, rural or urban residence, and other stratifiers. Presenting disaggregated data encourages population health researchers and public health planners to consider the intersections of determinants that create or ameliorate inequities for good health and inequalities in health outcomes. ${ }^{8}$

The recent release of 2017 TB surveillance data for Canada ${ }^{9}$ goes part way to meet these goals but falls short in consistently disaggregating data when reporting on treatment outcomes for patients with TB. The epidemiologic report and supplementary tables provide some stratified data; case counts and incidence rates are disaggregated by sex, province or territory, sex and age, country of origin and Indigenous group (First Nations, Métis or Inuit). These stratified data illustrate the greatest burdens of disease: $71.8 \%$ of cases involve patients who were born outside of Canada and the $17.4 \%$ of cases involving patients who are Indigenous and born in Canada are disproportionate to the size of the subpopulations. For example, the incidence rate of TB in First Nations patients was 34 times higher (17.1 per 100000 population in 2017) than in non-Indigenous patients who were born in Canada (0.5 per 100000 population). Patients who were Inuit had an incidence rate more than 400 times higher (205.8 per 100000 population). It would be valuable to disaggregate these data further to know more about the sex and age compositions of patients with TB within the foreign-born and Indigenous populations.

Critically, the data presented in the 2017 TB surveillance report for treatment outcomes (i.e., how Canada is doing in treating and curing TB in populations with the high burden of disease) are not disaggregated by age and sex or population. ${ }^{9}$ Essential information about public health and clinical responses for these high-burden populations is buried in the data across all cases in Canada. Nationallevel TB surveillance in Canada depends on the provinces and territories providing data to the federal government voluntarily. Although not required to provide their data under the Public Health Act of Canada, provinces and territories can, however, contribute to a more comprehensive approach to TB elimination by sharing stratified data on screening, treatment and outcomes among foreign-born, First Nations, Inuit and Métis populations in Canada, as well as collecting information on drug resistance and comorbidity. Information on drug resistance and comorbidity with HIV are also needed. For provinces and territories where case numbers are high, it would be possible to present these data for each of the 2 main subpopulations affected by sex, and by sex and age, without compromising confidentiality; where numbers are too small, aggregates by province or territory may be necessary for national reporting.

Researchers, clinicians and public health personnel in Canada continue to call for a set of national-level TB indicators for high-risk populations. ${ }^{10}$ In November 2018, experts gathered to propose an initial list of indicators of program performance for consideration (National Collaborating Centre for Infectious Diseases: unpublished data, 2018). Further consultation will be needed to reach agreements with all jurisdictions in the federation to determine a core set of indicators and recommendations for consistent data reporting at the national level to monitor progress towards eliminating TB.

With coordination and consistency across the provinces and territories, national-level TB surveillance reports could illustrate the value of consistent disaggregation of indicator data. This would inform directed and effective interventions where they are needed most to reduce inequalities. There are initiatives already underway to establish localized indicators. Community involvement in determining meaningful indicators is essential to these deliberations for different First Nations, Métis, Inuit - and potentially foreign-born communities. For example, populationspecific TB determinants were recently published by Dehghani and colleagues, ${ }^{11}$ and the findings show where the greatest improvements have been made in annual reduced incidence of TB.

Without a common aspiration for improved, meaningful data to inform public health action, monitoring and evaluation, Canada is likely to fall short of its goal of eliminating TB.

\section{Margaret J. Haworth-Brockman MSc}

Senior program manager, National Collaborating Centre for Infectious Diseases, University of Manitoba, Winnipeg, Man. 


\section{Yoav Keynan MD PhD}

Scientific lead, National Collaborating Centre for Infectious Diseases; Associate professor, Department of Medical Microbiology, University of Manitoba, Winnipeg, Man.

Cite as: CMAJ 2019 July 2;191:E743-4. doi: $10.1503 / \mathrm{cmaj} .72225$

\section{References}

1. Ottawa vows to eliminate tuberculosis in Inuit com munities by 2030. CBC News 2018 Mar. 22, updated 2018 Mar. 23. Available: www.cbc.ca/news/politics/ tuberculosis-philpott-obed-fight-1.4589028 (ac cessed 2018 June 18).

2. Halseth R, Odulaja OO. Addressing the challenge of latent tuberculosis infection among Indigenous peoples of Canada. Prince George (BC): National Collaborating Centre for Aboriginal Health; 2018. Available: www.nccih.ca/495/Addressing_the_challenge_of latent_tuberculosis_infection_among_Indigenous_ peoples_in_Canada.nccih?id=242 (accessed 2019 June 13).
3. King M. NCC Knowledge Exchange Forum: Towards TB elimination in Northern Indigenous communities. Winnipeg: National Collaborating Centre for Infectious Disease; 2018 Jan. 31-Feb. 1. Available: https://nccid.ca/ncc-knowledge-exchange-forum -towards-tb-elimination-in-northern-indigenous -communities/?hilite=\%27Malcolm $\% 27 \% 2$ C $\% 27$ King\%27 (accessed 2019 Mar. 7).

4. Essue BM, Milinkovic D, Birch S. Better data to drive more effective care for people with latent tuberculosis infection in Canada. CMAJ 2018;190:E700-1.

5. Framework towards tuberculosis elimination in low-incidence countries. Geneva: World Health Organization; 2014. Available: www.who. int/tb/publications/elimination_framework/en/ (accessed 2018 June 18).

6. Toms C, Stapledon R, Coulter C, et al. Tuberculosis notifications in Australia, 2014. Commun Dis Intell Q Rep 2017;41:E247-63.

7. Tuberculosis in England 2016 report (presenting data to end of 2015). London (UK): Public Health England; 2016. Available: www.tbalerts.org/ wp-content/uploads/2016/09/PHE_TB_Annual_ Report_2016.pdf (accessed 2018 June 18).

8. Pan-Canadian Health Inequalities Reporting Initiative. Key health inequalities in Canada: a national portrait - Executive summary. Ottawa: Public
Health Agency of Canada; 2018. Available: www. canada.ca/content/dam/phac-aspc/documents/ services/publications/science-research/key-health -inequalities-canada-national-portrait-executive -summary/hir-full-report-eng.pdf (accessed 2018 June 18).

9. LaFreniere $\mathrm{M}$, Hussain $\mathrm{H}, \mathrm{He} \mathrm{N}$, et al. Tuberculosis in Canada: 2017. Can Commun Dis Rep 2019;45: 68-74. Available: www.canada.ca/en/public-health/ services/reports-publications/canada-communicable -disease-report-ccdr/monthly-issue/2019-45/issue-2 -february-7-2019/article-4-tuberculosis-in-canada. html (accessed 2019 Mar. 8).

10. Heffernan C, Long R. Would program performance indicators and a nationally coordinated response accelerate the elimination of tuberculosis in Canada? Can J Public Health 2019;110: 31-5.

11. Dehghani K, Lan Z, Li P, et al. Determinants of tuberculosis trends in six Indigenous populations of the USA, Canada, and Greenland from 1960 to 2014: a population-based study. Lancet Public Health 2018;3:e133-42.

Competing interests: None declared.

Acknowledgements: The authors thank Shivoan Balakumar for his comments on an initial draft. 